\title{
Anti-conidial Germination Factors Induced in the Presence of Probenazole in Infected Host Leaves. III. Structural Elucidation of Substances A and C
}

\author{
Masaru Shimura, Sadaaki Mase, Michiaki Iwata, \\ Akira Suzuki, Tetsuro Watanabe, Yasuharu Sekizawa, \\ Toru SaSaKi, ${ }^{*}$ Kazuo Furihata, * Haruo SETO* \\ and Noboru OTAKE* \\ Research Laboratories, Meiji Seika Kaisha, Ltd., \\ Morooka-cho, Kohoku-ku, Yokohama 222, Japan \\ *Institute of Applied Microbiology, The University of Tokyo, \\ Bunkyo-ku, Tokyo 113, Japan \\ Received January 6, 1983
}

\begin{abstract}
The structures of substances $\mathrm{A}$ and $\mathrm{C}$ have been elucidated by chemical and spectroscopic analyses. Both compounds gave stearic acid on catalytic hydrogenation. Based on the analysis of $400 \mathrm{MHz}^{1} \mathrm{H}-\mathrm{NMR}$ spectral data, substance A was determined as 13-hydroxy-cis-9, trans-11, cis-15octadecatrienoic acid and substance $\mathrm{C}$ as 9-hydroxy-trans-10, cis-12, cis-15-octadecatrienoic acid.

Substance A was identical with a reduction product of 13-hydroperoxylinolenic acid prepared by treatment of $\alpha$-linolenic acid with soybean lipoxygenase.
\end{abstract}

Previously we have reported that four anticonidial germination substances A, B, C and D were isolated from rice plant leaves treated with probenazole and with the subsequent inoculation of fungal conidia of rice blast, ${ }^{1)}$ and that substance $\mathrm{B}$ was identical with $\alpha$ linolenic acid. ${ }^{2)}$

In this paper, we describe the structural elucidation of substances $\mathrm{A}$ and $\mathrm{C}$.

Substances $\mathrm{A}$ and $\mathrm{C}$ inhibited the germination of conidium of Pyricularia oryzae and A inhibited the multiplication of Xanthomonas campestris pv. oryzae on an agar plate. ${ }^{1)}$ From $700 \mathrm{~g}$ of rice plant leaves, about $23 \mathrm{mg}$ of $\mathrm{A}$ and $3 \mathrm{mg}$ of $\mathrm{C}$ were obtained.

$\mathrm{A}$ is a colorless syrup with a peculiar odour quite different from $B$. The formula $\mathrm{C}_{18} \mathrm{H}_{30} \mathrm{O}_{3}$ was assigned to $\mathrm{A}$ by an elemental analysis (Calcd for: C, $73.43 ; \mathrm{H}, 10.27$; O, $16.30 \%$. Found: C, 72.67; H, 9.52; O, $17.24 \%$ ), the ${ }^{13} \mathrm{C}-$ NMR spectrum of $A$, and the mass spectrum of the methyl ester of A. It showed a maximum peak at $236 \mathrm{~nm}$ with an absorption intensity $E_{1 \mathrm{~cm}}^{1 \%} 1140$. In the IR spectrum of A, a broad peak at $3350 \mathrm{~cm}^{-1}$ and a sharp peak at
$1710 \mathrm{~cm}^{-1}$ were observed to indicate the presence of a hydroxyl and a carboxyl group. These data are summarized in Table $I$ in comparison with $\mathrm{B}$ and $\mathrm{C}$. A is optically active showing $[\alpha]_{\mathrm{D}}^{25}=+4.8^{\circ}(c=1, \mathrm{MeOH})$. Methylation of A with diazomethane gave the substance A-I. The $R f$ value of A-I on a silicagel TLC plate developed with dichloromethane was 0.25 . Under this condition, A did not move at all. The mass spectrum of A-I gave peaks at $m / z 308\left(\mathrm{M}^{+}\right)$and 290 . Catalytic hydrogenation of A-I followed by a gas chromatographic analysis revealed the formation of three products; methyl stearate and two unknown compounds. These two unknown compounds were presumed to be partiallyreduced products of A-I on the basis of mass spectral data. These findings suggest that $A$ is an unsaturated fatty acid having a straight skeleton comprising 18 carbons.

The structure of A was finally established by $400 \mathrm{MHz}{ }^{1} \mathrm{H}-\mathrm{NMR}$ and $100 \mathrm{MHz}{ }^{13} \mathrm{C}-\mathrm{NMR}$ spectroscopic analyses. As summarized in Table II, 18 peaks were observed in the ${ }^{13} \mathrm{C}$ NMR spectrum of $A$, which indicated the 
Table I. The Physical Properties of Substances A, B and C

\begin{tabular}{llll}
\hline & \multicolumn{1}{c}{ Substance A } & \multicolumn{1}{c}{ Substance B } & Substance C \\
\hline Molecular formula & $\mathrm{C}_{18} \mathrm{H}_{30} \mathrm{O}_{3}$ & $\mathrm{C}_{18} \mathrm{H}_{30} \mathrm{O}_{2}$ & $\mathrm{C}_{18} \mathrm{H}_{30} \mathrm{O}_{3}$ \\
Molecular weight & 294.42 & 278.42 & 294.42 \\
$\mathrm{TLC} \mathrm{C}^{a}(1)$ & 0.83 & 0.92 & 0.72 \\
$(2)$ & 0.31 & 0.35 & 0.21 \\
$\mathrm{UV} \lambda_{\max }^{\mathrm{MeOH}} \mathrm{nm}\left(E_{1 \mathrm{~cm}}^{1 \%}\right)$ & $236(1140)$ & End absorption & $236(1180)$ \\
$\mathrm{IR} v_{\max }^{\mathrm{KBr}} \mathrm{cm}^{-1}$ & $3350,3010,2940$, & $3010,2920,2850$, & \\
& $2850,1710,1460$, & $1710,1455,1410$, & \\
& $1410,1260,1080$, & $1280,1060,935$, & \\
\hline
\end{tabular}

a Silica gel TLC: (1), ethyl ether; (2), chloroform-ethanol (95: 5).

TABle II. The ${ }^{13}$ C-NMR Spectral Data of Substance A

$\left.\begin{array}{ccl}\hline \begin{array}{c}\text { Chemical shifts } \\ \delta(\mathrm{ppm})\end{array} & \text { Multiplicity }^{a} & \text { Assignments }^{b} \\ \hline 14.1 & \mathrm{q} & \mathrm{C}-18 \\ 20.6 & \mathrm{t} & \mathrm{C}-17 \\ 24.5 & \mathrm{t} & \mathrm{C}-3 \\ 27.5 & \mathrm{t} & \mathrm{C}-8 \\ 28.7 & \mathrm{t} \\ 28.8 & \mathrm{t} \\ 28.9 & \mathrm{t}\end{array}\right\}$

a Multiplicity was determined by the INEPT method.

$b$ Based on ref 3 .

presence of one carbonyl carbon $(\delta 179.0), 6$ olefinic methine carbons $(\delta 135.0,134.8,132.8$, $127.7,125.8,123.6)$, one oxygenated methine carbon $(\delta 72.0), 9$ methylene carbons $(\delta 35.1$, $33.8,29.3,28.9,28.8,28.7,27.5,24.5,20.6)$ and one methyl carbon $(\delta 14.1)$. The $400 \mathrm{MHz}{ }^{1} \mathrm{H}$ NMR spectrum of $A$ is shown in Fig. 1. Corresponding with the ${ }^{13} \mathrm{C}-\mathrm{NMR}$ spectral data, the signals of 6 olefinic protons $(\delta 6.52$, $5.97,5.68,5.56,5.45,5.36)$, one oxygenated methine proton $(\delta 4.23), 9$ methylenes and one methyl $(\delta 0.97)$ were observed. The sequence of the carbon chain, and the position and geometry of the double bonds of A were deduced from an analysis of ${ }^{1} \mathrm{H}-\mathrm{NMR}$ spectral data, including the results of spin-decoupling experiments, which revealed the presence of the partial structures shown in Fig. 2. The remaining three unresolved methylene groups at $\delta 1.32$ must exist between (I) and (II). The coupling constants $J_{9,10}=11.2 \mathrm{~Hz}, \quad J_{11,12}=$ $15.2 \mathrm{~Hz}$ and $J_{15,16}=11.2 \mathrm{~Hz}$ are indicative of a cis, trans, cis configuration at these double bonds. Thus, in consideration of the other data described, the structure of A was established as 13-hydroxy-cis-9,trans-11, cis-15-octadecatrienoic acid (Fig. 3).

This compound has been previously reported by Gardner et al. with NMR spectral data. ${ }^{4)} \mathrm{A}$ and the reported compound agree very well in their NMR spectral data. They obtained this compound by the reduction of 13-hydroperoxylinolenic acid. In order to confirm the identity of A with the reported compound, 13-hydroperoxylinolenic acid was enzymically prepared by soybean lipoxygenase with $\alpha$-linolenic acid as the substrate, and the product was reduced by sodium borohydride. A spot of A gave the same $R f$ value as that of the compound prepared on silica gel TLC developed with ethyl ether (water satd.)hexane $(9: 1)$ and differentiated from that of 13-hydroperoxylinolenic acid. The bioactivity of $\mathrm{A}$ and the prepared compound against Pyricularia oryzae was quite similar. The mass 


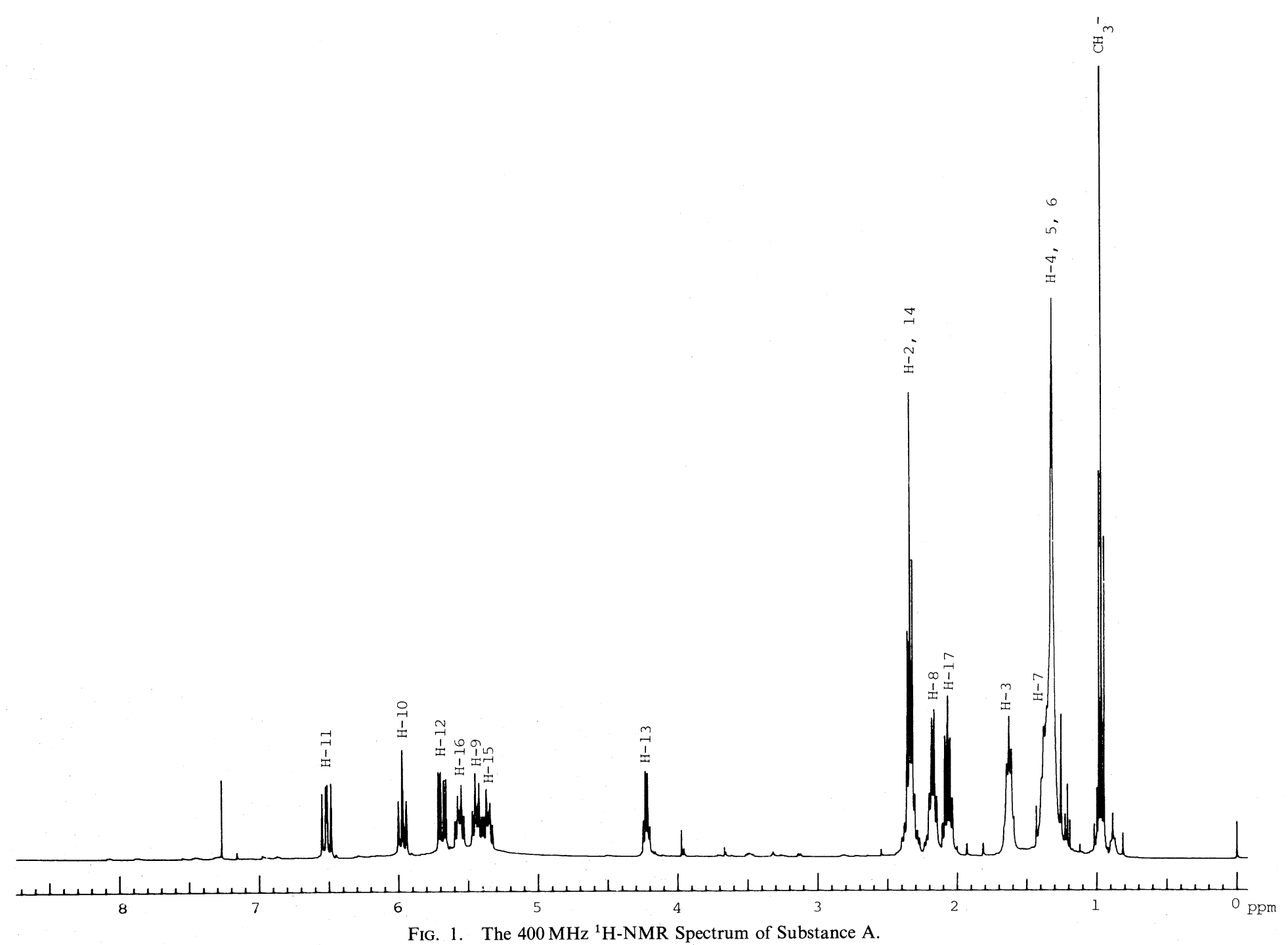




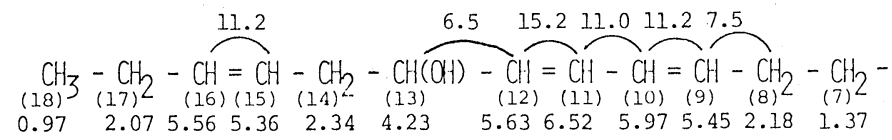

(II)

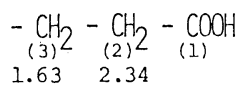

The numbers are coupling constants (at the top, $\mathrm{Hz}$ ), carbon numbers (in parentheses) and chemical shifts (at the bottom, $\delta, \mathrm{ppm}$ ).

FIG. 2.

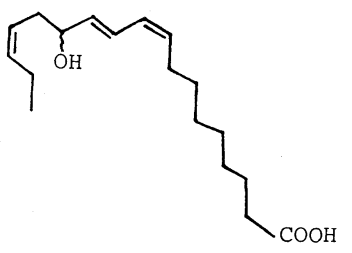

Substance A

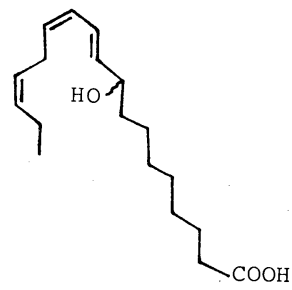

Substance C

FIG. 3. The Structures of Substances A and C.

spectrum of A-I was completely identical with that of the methyl ester of the prepared compound.

$\mathrm{C}$ is a colorless syrup. It showed a maximum peak at $236 \mathrm{~nm}$ with an absorption intensity of $E_{1 \mathrm{~cm}}^{1 \%} 1180$. Upon treatment with diazomethane, $\mathrm{C}$ gave a methyl ester $(\mathrm{C}-\mathrm{I})$. The peaks at $m / z 308\left(\mathrm{M}^{+}\right)$and 290 were also observed in the mass spectrum of C-I. Catalytic hydrogenation of $\mathrm{C}$-I followed by gas chromatographic analysis revealed the formation of three products, methyl stearate and two compounds, which were presumed to be partiallyreduced products of $\mathrm{C}$-I. These experimental results suggest that $\mathrm{C}$ is closely related to $\mathrm{A}$; namely, it is an unsaturated fatty acid having a skeleton comprising 18 carbons and is different from A by the position of a hydroxyl group and/or double bonds. The ${ }^{1} \mathrm{H}-\mathrm{NMR}$ spectrum of $\mathrm{C}$ is very similar to that of $\mathrm{A}$ (Fig. 4). In this spectrum, the signals of 6 olefinic protons $(\delta 5.32,5.41,5.41,5.69,5.99,6.51)$, one oxygenated methine proton $(\delta 4.17), 9$ methylenes and a methyl $(\delta 0.97)$ can be observed. Spin decoupling experiments proved the following two groups (Fig. 5). The remaining four methylene groups observed at $\delta 1.32$ must exist between (I) and (II) to give the structure as 9-hydroxy-10,12,15octadecatrienoic acid. The magnitude of the coupling constants, $J_{10,11}=15.2 \mathrm{~Hz}, J_{12,13}=$ $11.0 \mathrm{~Hz}$ and $J_{15,16}=11.0 \mathrm{~Hz}$, are indicative of trans, cis, cis stereochemistry at these double bonds. Thus, the structure of $\mathrm{C}$ has been proved to be 9-hydroxy-trans-10, cis-12, cis15-octadecatrienoic acid (Fig. 3).

It has been reported ${ }^{4)}$ that soybean lipoxygenase oxidized linolenic acid primarily at carbon 13, with a small degree of oxidation occurring at carbon 9. Since substance A could be obtained by reduction of 13-hydroperoxylinolenic acid, it can be supposed that $\mathrm{A}$ and C were formed via a corresponding hydroperoxide of linolenic acid, and the lipoxygenase in rice plants, although not so far reported, might participate in the formation of these hydroperoxides. Therefore, it will be worthwhile to determine the activity of lipoxygenase in the lesion site on rice plant leaves for future studies. Ohata has describ$\mathrm{ed}^{5)}$ that fatty acid metabolism was accelerated by an infection with Cochliobolus miyabeanus, a main casual fungus of brown spot of rice, in the resistant cultivar of the rice 


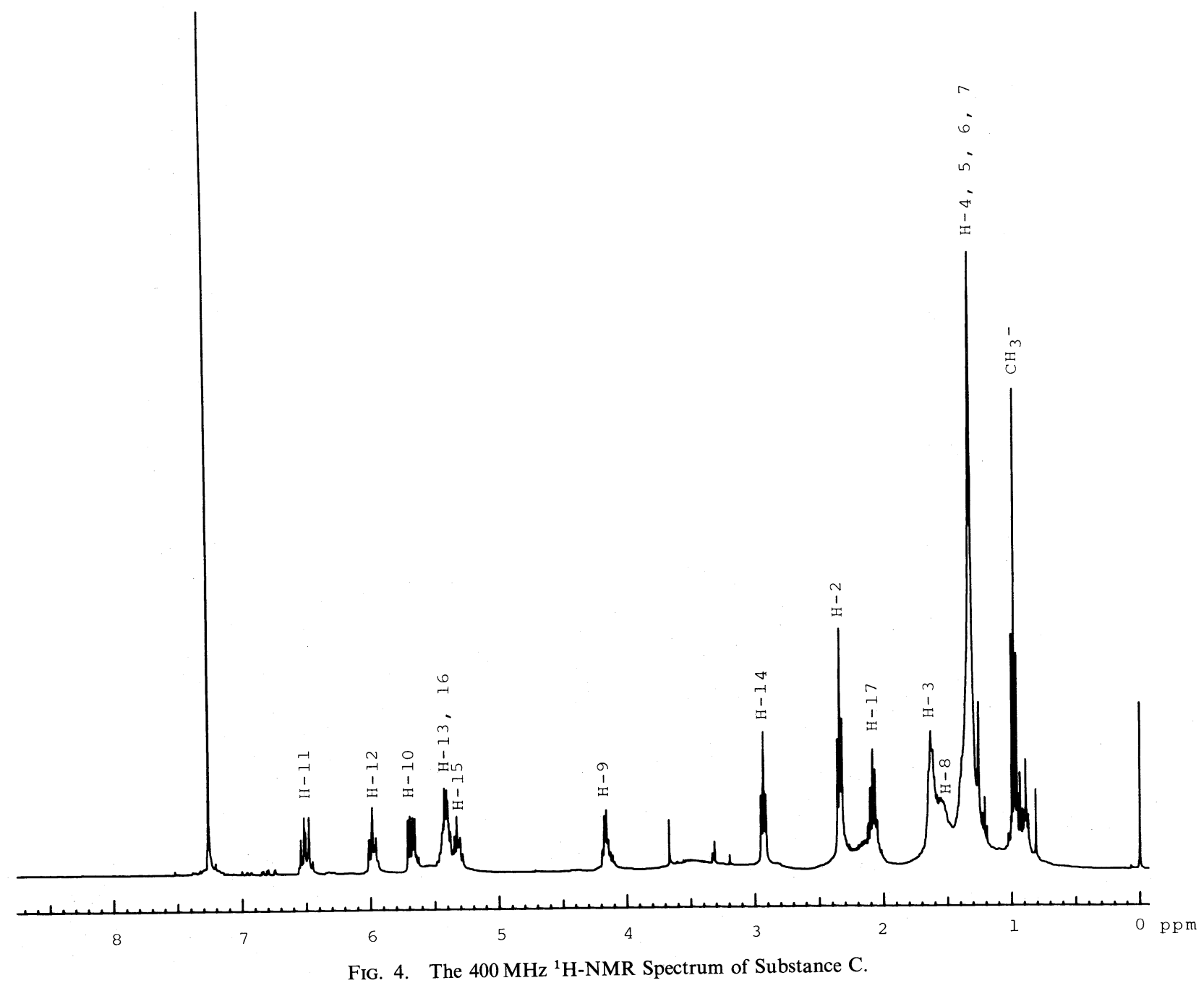




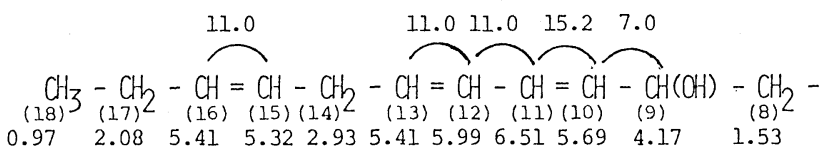

(II)

$$
\begin{gathered}
-\mathrm{CH}_{2}-\underset{(2)}{\mathrm{CH}_{2}}-\underset{(1)}{\mathrm{COOH}} \\
1.63 \\
2.34
\end{gathered}
$$

The numbers are coupling constants (at the top, $\mathrm{Hz}$ ), carbon numbers (in parentheses) and chemical shifts (at the bottom, $\delta, \mathrm{ppm}$ ).

FIG. 5.

plant. In addition to substances $\mathrm{A}, \mathrm{B}$ and $\mathrm{C}$, other bioactive substances related to fatty acids may exist in the rice plant. Substance $\mathrm{D}^{1)}$ or the hydroperoxide of linolenic acid may be members of these. The bioactivity of 13-hydroperoxylinolenic acid against Pyricularia oryzae was same with that of A. The reason that the hydroperoxide of linolenic acid had not yet been isolated from rice plant may be due to its instability. A rapid nonenzymical conversion of 13-hydroperoxylinolenic acid to substance A by cysteine was observed. ${ }^{6)}$ It can be reasonably assumed that these bioactive substances accumulating in the lesion site of the rice plant function as antimicrobial agents against phytopathogens including Pyricularia oryzae and Xanthomonas campestris pv. oryzae.

\section{EXPERIMENTAL}

For spectroscopic analyses, the following instruments were used; a Hitachi 557 spectrophotometer for UV spectra, a Hitachi 215 recording spectrometer for infrared spectra, a Hitachi M-80 mass spectrometer for mass spectra, a JEOL FX-400 (400 MHz for ${ }^{1} \mathrm{H}-\mathrm{NMR}$ and $100 \mathrm{MHz}$ for ${ }^{13} \mathrm{C}-\mathrm{NMR}$ ) for $\mathrm{NMR}$ spectra and a Shimadzu GC-7AG for gas chromatographic analysis.

Methylation of substances $A$ and $C$. To one $\mathrm{ml}$ of an etherial solution containing $2 \mathrm{mg}$ of $\mathrm{A}$ or $\mathrm{C}$, was added an etherial solution of diazomethane. The reaction mixture, after being kept for about an hour at room temperature, was concentrated to give an oily substance. The resultant products (A-I or C-I) were analyzed by TLC and mass spectroscopy. TLC: Dichloromethane; A-I, $R f 0.25, \mathrm{C}-\mathrm{I}$, Rf 0.21 .

TLC analysis. Silica gel plate No. 5714 (Merck) was used. $\mathrm{A}$ and $\mathrm{C}$ or related substances were detected by UV light (Manaslu Light $2536 \AA$ ) or viewed as dark brown spots by spraying dilute sulfuric acid and heating for several minutes.

Catalytic hydrogenation. A-I or C-I ( $1 \sim 2 \mathrm{mg})$ was dissolved in $1 \mathrm{ml}$ of methanol and hydrogenated with hydrogen gas, using a few milligrams of palladium black as the catalyst under atmospheric pressure. After an hour, the reaction mixture was filtered and the filtrate was concentrated. The residue was subjected to gas chromatography and mass spectroscopy. The gas chromatogram of hydrogenated A-I gave three peaks; retention times, 8.0 min (identical with methyl stearate), $40.4 \mathrm{~min}$ and 47.2 min. In the mass spectrum of hydrogenated A-I, the peaks corresponding to those of methyl stearate $\left(m / z 298\left(\mathrm{M}^{+}\right)\right)$, dihydro derivative of A-I $\left(m / z 292\left(\mathrm{M}^{+}-18\right), 241\right.$ $\left.\left(\mathrm{M}^{+}-69\right)\right)$, and the tetrahydro derivative of A-I $(\mathrm{m} / z 312$ $\left.\left(\mathrm{M}^{+}\right), 294,243\right)$ were observed. The gas chromatogram of hydrogenated C-I gave three peaks; retention times, 8.0 min, $36.8 \mathrm{~min}$ and $39.8 \mathrm{~min}$. In the mass spectrum of hydrogenated C-I, the peaks corresponding to those of methyl stearate $\left(m / z 298\left(\mathrm{M}^{+}\right)\right)$, the dihydroderivative of C-I $\left(m / z 281\left(\mathrm{M}^{+}-29\right), 209\left(\mathrm{M}^{+}-101\right)\right)$, and the tetrahydro derivative of C-I $\left(m / z 312\left(\mathbf{M}^{+}\right), 283,211\right)$ were observed.

Gas chromatographic analysis. The reduction product described above was dissolved in $1 \mathrm{ml}$ of hexane and $2 \mu \mathrm{l}$ of it was injected into a gas chromatograph equipped with a flame ionization detector. The gas chromatographic conditions were: column, $3 \mathrm{~mm} / 2 \mathrm{~m}$ glass column; supporting material, Gas Chrome P 80/100 mesh; liquid phase, 15\% EGSS Y; carrier gas, nitrogen $60 \mathrm{ml} / \mathrm{min}$; column temperature, $200^{\circ} \mathrm{C}$. Under these conditions, authentic methyl stearate gave a single peak with a retention time of 8.0 $\min$.

Preparation of 13-hydroperoxy linolenic acid. One hundred mg of $\alpha$-linolenic acid (Wako Pure Chemicals) was dissolved in $500 \mathrm{ml}$ of $0.1 \mathrm{M} \mathrm{NH}_{4} \mathrm{Cl}-\mathrm{NH}_{4} \mathrm{OH}$ buffer at $\mathrm{pH}$ 9.0. Lipoxygenase (Tokyo Chemicals, $100 \mathrm{mg}$ ) was added to the solution and incubated in an ice bath for 1 hour with stirring. ${ }^{7)}$ The reaction mixture was acidified and extracted with $500 \mathrm{ml}$ of ethyl ether. TLC analysis indicated the 
formation of a main product in addition to the starting material and other minor by-products. The extract was concentrated and chromatographed on Diaion HP20AG equilibrated with methanol. The fractions giving a spot at Rf 0.88 on silica gel TLC with ethyl ether were combined and concentrated. After subsequent purification by preparative TLC $(20 \times 20 \mathrm{~cm}$, silica gel, ethyl ether $), 25 \mathrm{mg}$ of the main product was obtained as a colorless oily substance, which was positive to thiobarbituric acid test for hydroperoxide. ${ }^{8)}$ This substance has a bioactivity similar to that of substance A against Pyricularia oryzae. TLC: ethyl ether (water satd.)-hexane (2:1); Rf 0.35 .

Reduction of hydroperoxide by sodium borohydride. Ten $\mathrm{mg}$ of the hydroperoxide described above was dissolved in $1 \mathrm{ml}$ of methanol, cooled to $0^{\circ} \mathrm{C}$ and reduced with $20 \mathrm{mg}$ of sodium borohydride. ${ }^{9)}$ After $20 \mathrm{~min}$ at $0^{\circ} \mathrm{C}$ and $40 \mathrm{~min}$ at room temperature with stirring, the reaction mixture was diluted with water. After partial removal of the methanol by evaporation, the product was extracted with ethyl ether under the acidic condition. The extract was concentrated and dried in a desiccator to yield a colorless oily substance. This substance inhibited completely the conidial germination of Pyricularia oryzae at a concentration of $200 \mu \mathrm{g} / \mathrm{ml}$. MS (methyl ester): $m / z 308\left(\mathrm{M}^{+}\right), 290$. TLC: ethyl ether (water satd.)-hexane $(2: 1) ; R f 0.29$. These data coincided exactly with those of substance A.
Acknowledgments. The authors thank Mr. Y. Kodama and Miss. S. Miki, Analysis Group, Research Laboratories, Meiji Seika Kaisha Ltd., for their measurement of mass spectra.

\section{REFERENCES}

1) M. Shimura, M. Iwata, N. Tashiro, Y. Sekizawa, Y. Suzuki and T. Watanabe, Agric. Biol. Chem., 45, 1431 (1981).

2) Y. Sekizawa, M. Shimura, A. Suzuki and M. Iwata, Agric. Biol. Chem., 45, 1437 (1981).

3) G. C. Levy, "Topics in Carbon-13 NMR Spectroscopy," Vol. 2, John Wiley and Sons, New York, 1976 , p. 82.

4) H. W. Gardner and D. Weisleder, Lipids, 7, 191 (1972).

5) K. Ohata and C. Kubo, Bull. Shikoku, Agric. Exp. Stn., No. 28, 17 (1974).

6) M. Iwata et al., unpublished data.

7) J. Sekiya, S. Numa, T. Kajiwara and A. Hatanaka, Agric. Biol. Chem., 40, 185 (1976).

8) Z. A. Placer, L. L. Cushman and B. C. Johnson, Anal. Biochem., 16, 359 (1966).

9) M. Hamberg and B. Samuelson, J. Biol. Chem., 242, 5329 (1967). 